\title{
Forecasting a Cyclical Downturn (Recession) in the US Economy Using a Mathematical Model of Hyman Minsky's Theory of Financial Instability
}

\author{
Foreign Member of the RAS A. A. Akaev ${ }^{a, *}$ and Academician of the RAS V. A. Sadovnichii ${ }^{b, * *}$ \\ Received June 18, 2020; revised July 21, 2020; accepted July 22, 2020
}

\begin{abstract}
By using the US economy as an example, the paper shows how the COVID-19 pandemic has changed its short-term dynamics, causing a deep crisis recession in 2020 rather than the expected short-term and shallow recession in 2022 caused by the inflation of the financial bubble during the credit expansion that followed the financial and economic crisis of 2008-2009. To predict the latter scenario, which is natural for the US economy, the authors first developed a mathematical model based on Hyman Minsky's theory of financial instability, which can serve to manage the processes of credit expansion and contraction in an unstable economy.
\end{abstract}

Keywords: economic dynamics, speculative growth lending, Minsky's theory of financial instability, management of credit expansion and contraction, mathematical model for forecasting a cyclical downturn (recession) in an unstable economy

DOI: $10.1134 / \mathrm{S} 1064562420050245$

An opinion that a deep crisis (or, possibly, a recession) would occur in the US economy in the nearest future was expressed by numerous prominent economists and experts. Indeed, stable growth in the US economy was observed starting in 2010. Over the first seven years (2010-2016), the economy grew at an average rate of about $2 \%$ per year, while, in 2017-2018 under President Donald Trump, the economic growth accelerated due to the tax cut in business and increased to 2.4 and $2.9 \%$ per year. However, in 2019, the growth rate reduced to $2.3 \%$ and the IMF predicted a further decrease to $1.9 \%$ in 2020 [1]. It can be seen that this prediction confirmed the experts' hypothesis that the current business cycle starting after the "large recession" in 2009 was coming to an end, since its duration for the US economy is 8-12 years.

As early as the 1970s, the outstanding American economist Hyman Minsky [2] developed a theory of financial instability, which most adequately describes modern financial markets. Minsky's theory states that financial markets can generate their own (endogenous) forces causing self-sustained waves of credit

\footnotetext{
${ }^{a}$ Institute of Complex System Mathematical Research, Lomonosov Moscow State University, Moscow, 119992 Russia ${ }^{b}$ Faculty of Mechanics and Mathematics, Lomonosov Moscow State University, Moscow, 119991 Russia

*e-mail: askarakaev@mail.ru

**e-mail: info@rector.msu.ru
}

expansion and asset price inflation, which are necessarily followed by waves of credit contraction and asset price deflation [2]. This is well illustrated by the plot of gross private investments in the US economy presented in Fig. 1, which clearly shows the corresponding investment expansions (1991-2000, 2002-2006, 2009-2018) and contractions (2000-2002, 20062009) observed over the past 30 years. Time points (e.g., 2000 and 2006) at which an expansion phase in credit cycles passes into a contraction phase are known as Minsky moments.

Obviously, the economic growth slows down at Minsky moments, which may lead to a significant downturn, as in 2001, or even to a deep recession, as occurred in 2009. All these features are shown in Fig. 2. It can be seen that the growth rate in 2001 decreased to $1 \%$ as compared with $4 \%$ in 2000 . In 2009 , due to the financial crisis of 2008, there was a deep recession, when the growth rate fell to almost $-3 \%$. However, in 2010 , due to the massive injection of liquidity into the banking sector and broad stimulation of investment expansion, the GDP growth rate exceeded $2.5 \%$ and remained at $2 \%$ per year on average up to 2017 , which marked the beginning of stable growth, reaching $3 \%$ in early 2019.

According to Minsky's theory of financial instability [2], the economic dynamics is determined to a large degree by how firms finance their investment in fixed capital. As a rule, secured financing from their own development assets prevails at the beginning of the expansion stage of a business cycle. Then, as sales 


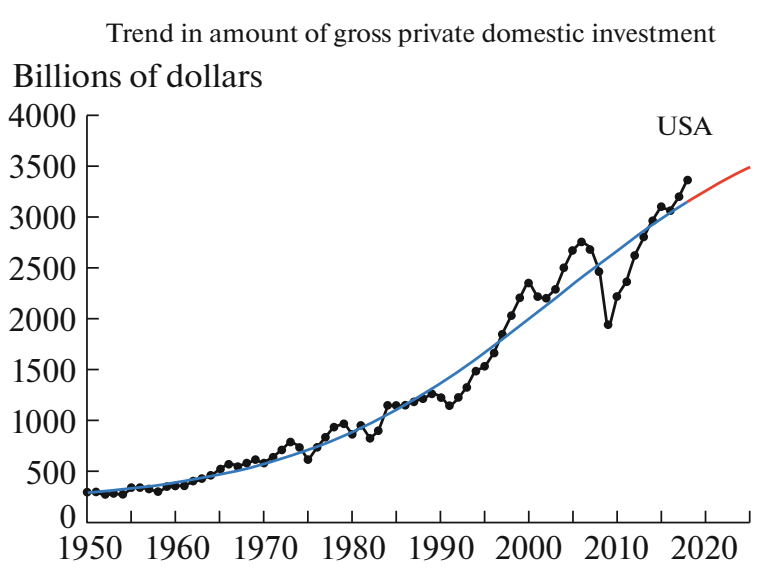

Fig. 1. Motion of cycles of investment expansions and contractions in the US economy. Source: https://apps. bea.gov/iTable/iTable.cfm?reqid $=19 \&$ step $=2 \#$ reqid $=19$ $\&$ step $=2 \&$ isuri $=1 \& 1921=$ survey

grow, firms actively switch to external financing based on bank loans. In this case, widely used are elements of speculative financing or even Ponzi schemes [2], when new loans are necessary for paying off available debts. An increase in the fraction of speculative loans in total financing of business leads to higher asset prices and the growth of investment [2]. It is this process that has recently been observed in the US economy (see Fig. 1).

A consequence of this process is the growth of the employment rate and demand in the economy and higher profits in business, which, in turn, convince businessmen and bankers of the utility of speculative financing, which brings good money. Such positive feedback reactions lead to self-reinforcing spiral of credit expansion and economic growth. However, this process gradually generates heavy debts and, at a certain time, known as a Minsky moment, leads to firms incapable of repaying their debts [2]. Starting at this moment, credits and investment are contracted, which eventually results in an economic downturn. This comprises the endogenous tendency of a capitalist economy to financial instability. Minsky adopted and developed Keynes' investment theory of business cycles [3], supplementing it with his own financial theory of investment [2]. Thus, the mechanism of investment financing is the main source of economic instability discovered and explained by Keynes and Minsky.

Minsky showed that, in the absence of control, both credit expansion and contraction can continue until the onset of a financial and economic crisis. Since financial markets are systems with inherent (endogenous) instability, the main task of a Central Bank (CB) is, primarily, to ensure the financial stability of the crediting system and, secondarily, to control price stability. Thus, the task of CB is to prevent excessive credit expansion or contraction [4]. The second

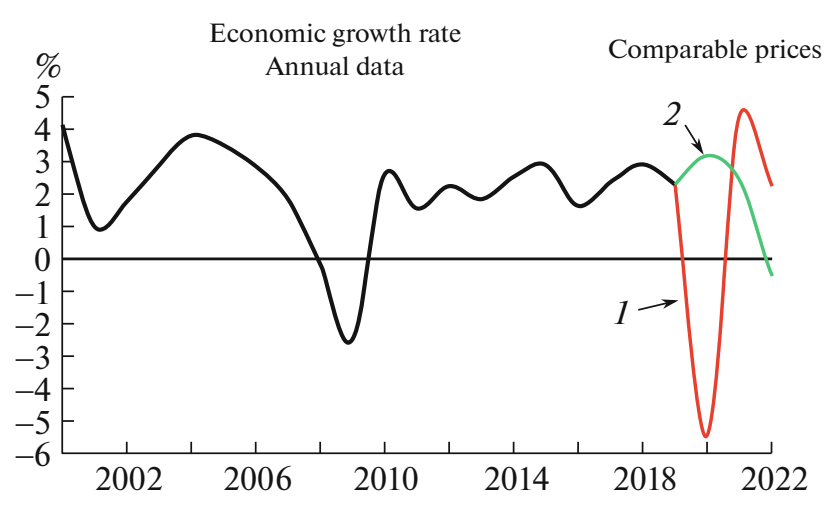

Fig. 2. Curve illustrating the growth rate of the US economy with 2020-2022 forecast. Source: https://apps. bea.gov/iTable/iTable. .fm? reqid $=19 \&$ step $=2 \#$ reqid $=19$ $\&$ step $=2 \&$ isuri $=1 \& 1921=$ survey

part of this task is handled by CB much better than the first one.

Since political leaders are interested in higher rates of economic growth, they always pressure $\mathrm{CB}$ into promoting credit expansion. This also meets the wishes of the business community. However, this policy is gradually transformed into a destabilizing factor leading to a critical Minsky moment. At present, this process has occurred in the US economy, where the Federal Reserve System is under constant pressure from President Trump, who desperately needs the maximum possible growth rate in the presidential election year. Accordingly, he calls for the Federal Reserve to cut interest rates "to zero or less," believing that this would help refinance investor debts and further expand credit, leading to the growth of the economy.

In practice, over 2019 the Federal Reserve cut the interest rate by 0.25 percentage point three times in a row down to 1.5-1.75, which was for the first time from 2008. The Federal Reserve explained this not by the US economy facing a recession threat, but rather by the low rate of inflation, decline in the world economy, and the world trade uncertainty. Some Federal Reserve managers criticized the mitigation of the monetary policy, considering it unnecessary and even capable of causing negative side effects. However, the coronavirus pandemic in early 2020 abruptly changed the situation. Immediately after a dramatic decline of stock prices, on March 10, 2020, the Federal Reserve cut the interest rate to $1.0-1.25 \%$ and, five days later, to $0.0-0.25 \%$. Simultaneously, the Federal Reserve launched a $\$ 700$ billion quantitative easing program. Moreover, on April 10, 2020, the Federal Reserve launched a program of up to $\$ 2.3$ trillion to provide loans for supporting the US economy and population.

Thus, the process of debt creation is an important macroeconomic characteristic, which has to be carefully monitored [4]. Lending is the basis for accelerat- 


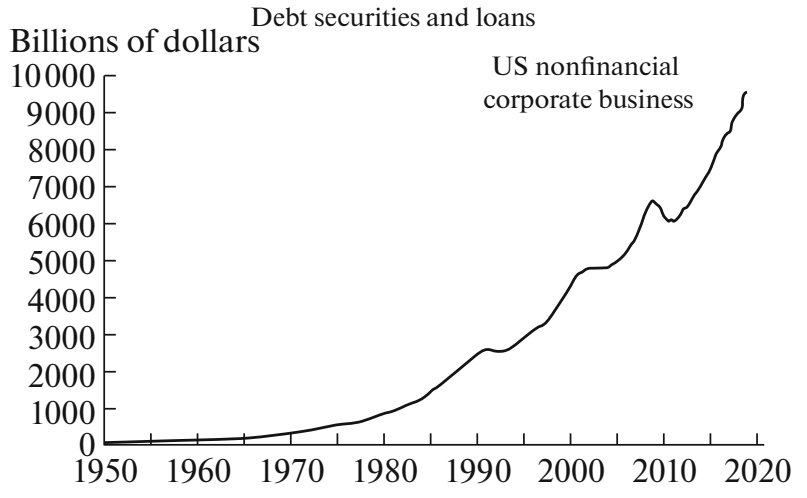

Fig. 3. Dynamics of debt securities and loans in US corporate business. Source: http://www.economagic.com/emcgi/data.exe/frbZ1/FL104104005

ing the economic growth and, at the same time, a cause of financial instability [4]. The curve illustrating the growth of debt securities and loans in corporate business (see Fig. 3) clearly reveals Minsky moments (1991, 2001, and 2008) with switching from credit expansion to credit contraction phases, which led to certain stabilization or even a reduction in the amount of debts by clearing the financial system from excessive debts. It is also well seen that the amount of unpaid debts grows rapidly (exponentially) starting in 2012 (see Fig. 3), which suggests approaching the next Minsky moment.

Thus, speculative growth lending has been observed in the US economy in recent years, which was facilitated by low-interest loans resulting from the Federal Reserve cutting the interest rate. In this paper, we propose a simple mathematical model based on the key principles of Minsky's theory of financial instability that makes it possible to predict the onset of a financial crisis (next Minsky moment) and the subsequent economic downturn.

First, to describe the dynamics of investment financing in an expansion phase, we use the differential equation

$$
\begin{aligned}
\frac{d I(t)}{d t} & =j I^{p}(t), \quad j=\mathrm{const} ; \\
p & =\mathrm{const}, \quad p>1,
\end{aligned}
$$

where $I(t)$ is the current investment in the economy. Equation (1) describes the dynamics of a self-reinforcing process with positive feedback. The solution of Eq. (1) has the form

$$
I_{e}(t)=\left\{j(p-1) \cdot\left[\frac{1}{j(p-1) I_{0}^{p-1}}+T_{0}-t\right]\right\}^{-\frac{1}{p-1}},
$$

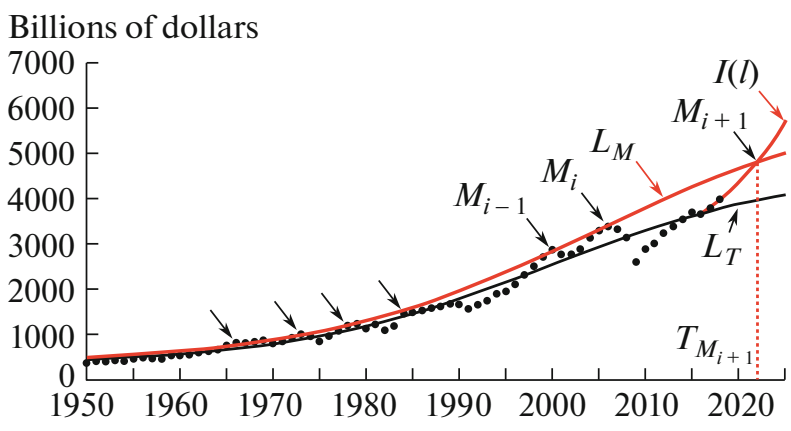

Fig. 4. Envelope of the investment curve and investment expansion determining moments of financial instability. Source: US Bureau of Economic Analysis.

where $T_{0}$ is the beginning of the credit expansion phase in the current cycle and $I_{0}$ is the initial amount of investment.

The approximation of the investment expansion curve on the segment 2016-2019 (see Fig. 4) with the use of formula (2) yields the following estimates of the constant parameters: $T_{0}=2016, I_{0}=\$ 3.67$ trillion, $j=4.86 \times 10^{-6}$, and $p=2.1$. Next, we extrapolate the investment growth curve with the help of formula (2). However, this growth is bounded by the forthcoming Minsky moment $\left(M_{i+1}\right)$, which lies on the envelope curve $L_{M}$ passing through all preceding Minsky moments $\left(M_{i}, M_{i-1}, \ldots, M_{i-k}\right)$, as shown in Fig. 4. Here, $M_{i-k}$ is the first Minsky moment in the preceding Kondratieff long wave. This envelope curve, like the trend curve $L_{T}$, is well approximated by the logistic curve

$$
I_{T}(t)=I_{T_{1}}+\frac{I_{T_{2}}}{1+v_{T} \exp \left[-\vartheta_{T}\left(t-T_{\mathrm{B}}\right)\right]} .
$$

Using actual data on investment dynamics in the US economy from 1950 to 2019 (see Fig. 4), the following parameter estimates for the logistic curve (3) were obtained by applying the least squares method: $L_{T}-T_{\mathrm{B}}=1950, I_{T_{1}}=339.6, I_{T_{2}}=4323.5, v_{T}=37.2$, $\vartheta_{T}=0.073, \quad L_{M}-T_{\mathrm{B}}=1950, \quad I_{M_{1}}=322.7, \quad I_{M_{2}}=$ $5941.8, \vee_{M}=35.5$, and $\vartheta_{M}=0.065$.

The intersection of the investment curve and the curve envelope $L$ (see Fig. 4) yields the forthcoming Minsky moment $\left(M_{i+1}\right)$, which corresponds to roughly March 14, 2022.

At approximately this time, we expect the next financial crisis in the US economy and the beginning of a credit contraction phase. to describe the dynamics of investment squeeze $\left(I_{S}\right)$, we earlier derived a special formula for the recession stage of a Kondratieff long wave [4]: 


$$
=I_{M} \exp \left\{-\left[1-\lambda_{0}\left(t-T_{M}+\frac{1}{\lambda_{0}}\right) e^{-\lambda_{0}\left(t-T_{M}\right)}\right]\right\},
$$

where $I_{M}$ is the maximum predicted amount of investment at the future Minsky moment, $T_{M}$ is the predicted future Minsky moment, and $\lambda_{0}$ is a constant parameter; previously, we found the estimates $T_{M}=$ March 14, 2022 and $I_{M}=\$ 4.81$ trillion.

The parameter $\lambda_{0}$ in approximating formula (4) can be found using a similar recession stage (2000-2002) in the 1991-2002 investment cycle. The resulting estimate is $\lambda_{0}=2.7$. Thus, we have two approximating formulas (3) and (4), which approximately describe a credit expansion phase and the subsequent credit contraction phase, respectively, in investment financing after the beginning of stable growth in 2016 (see Fig. 4). These formulas can be used for short-term predictions of the investment $I(t)$ in the US economy.

Finally, to predict the rate of economic growth, we use the production function $(\mathrm{PF})$

$$
Y=\gamma K^{\alpha}(A L)^{1-\alpha+\delta},
$$

where $Y(t)$ is the current amount of the national income (GDP), $K(t)$ is the fixed capital, $L(t)$ is the number of people occupied in the economy, $A(t)$ is technological progress, $\alpha$ is the fraction of capital in GDP, $\delta$ is a parameter characterizing an increasing return to scale $(\delta>0)$, and $\gamma$ is a normalizing coefficient. PF (5) was verified for the US economy over the period from 1946 to 2018 by using series of major factors ( $K, A$, and $L$ ) taken from the World Bank database [6] in comparable prices. More specifically, by applying the least squares method, the coefficient $\gamma$ and the parameters $\alpha$ and $\delta$ were estimated as $\gamma=0.069, \alpha=$ 0.622 , and $\delta=0.167$. The approximation error was at most $0.05 \%$. Therefore, PF (5) can be used for shortterm predictions of the GDP dynamics or the rate of GDP growth, which is more common and more illustrative for comparison purposes.

Accordingly, by using logarithmic differentiation, it is better to write PF (5) in the rate form

$$
q_{Y}=\alpha q_{K}+(1-\alpha+\delta)\left(q_{A}+q_{L}\right),
$$

where

$$
\begin{gathered}
q_{Y}=\dot{Y} / Y, \quad q_{K}=\dot{K} / K, \\
q_{A}=\dot{A} / A, \quad q_{L}=\dot{L} / L .
\end{gathered}
$$

Since the accumulation of the capital $K(t)$ is described by the equation

$$
\begin{gathered}
\qquad \frac{d K}{d t}=I(t)-\mu K, \\
\text { we have } \quad q_{K}=\dot{K} / K=\frac{I(t)}{K(t)}-\mu .
\end{gathered}
$$

In [5], $\mu$ was estimated as $\mu \cong 0.056$. Substituting (7) into (6), we obtain the final equation for computing the rate of economic growth:

$$
q_{Y}=\alpha\left(\frac{I}{K}-\mu\right)+(1-\alpha+\delta)\left(q_{A}+q_{L}\right)
$$

The forecast investment trajectory $I(t)$ in this equation was computed by sequentially applying predictive formulas (3) and (4). The required values of $K(t), A(t)$, and $L(t)$ were obtained by extrapolating their current values from the database [6] to a short-term period (2020-2022) with the use of a second-degree polynomial. The growth rates $q_{A}$ and $q_{L}$ were calculated using formulas (6a) in terms of finite differences. As a result, the predictive computations based on formula (8) yielded a trajectory of the US GDP rate over 20202022, which is shown in Fig. 2 (curve 2).

An analysis of the forecast portion of the curve (see Fig. 2) suggests that, in the absence of the pandemic, the rate of economic growth in 2020 would have increased by up to a maximum value of $3.2 \%$, which was anticipated by President Trump for his convincing victory in the November presidential election. Then there would inevitably be a financial crisis caused by the trajectory of accumulated outstanding debt going beyond the Minsky critical envelope in March, 2022. The financial crisis and the start of a credit contraction process at the Minsky moment (March 14, 2022) would be followed by a sharp recession of the economy, which would complete at an insignificant recession rate of $0.5 \%$, according to the predictive computations. Next, the powerful influence of innovative digital technologies of the fourth industrial revolution would lead to a fast recovery and subsequent stable growth of the economy at rates somewhat greater than $3 \%$ per year. However, the pandemic completely changed the described economic dynamics in the short term. The US economy is in recession. In the first quarter of the current year, it contracted at an annualized rate of $4.8 \%$, and a recession rate of 4 to $6 \%$ is predicted over 2020 as a whole.

In response to the COVID-19 pandemic, the US government and Congress appropriated an unprecedented $\$ 3$ trillion for emergency assistance for people and businesses. Added to the money provided by the US Federal Reserve, the total sum for supporting the US economy was about $\$ 7$ trillion, which amounts to nearly $35 \%$ of the US GDP. It can be seen that Keynesian recipes of economic rescue during crises work unfailingly. All these incentives create conditions for the US economy returning to the pre-crisis level as early as 2022 .

Taking into account the indicated financial investment in the US economy, we predicted the dynamics of the US economy growth rate over 2020-2022 with the help of the mathematical models described in [7], which are most suitable for the current scenario of 
economic development. The forecast results are presented in Fig. 2 (curve 1). Inspection of curve 1 shows that the recession rate in 2020 will be $5.5 \%$, but a recovering growth rate of $4.3 \%$ is expected in 2021 with the subsequent decrease to $2.3 \%$ in 2022 . Next, stable long-term growth of the economy will occur, as was noted above.

\section{FUNDING}

This work was performed at the Institute of Complex System Mathematical Research of Moscow State University and was supported by the Russian Science Foundation, grant no. 20-61-46004, the project "Global development and limits of growth in the 21st century: Simulation and forecast."

\section{REFERENCES}

1. World Economic Outlook, July 23, 2019. www.elibrary.imf.org

2. H. P. Minsky, Stabilizing an Unstable Economy (McGraw Hill, New York, 2008).

3. J. M. Keynes, The General Theory of Employment, Interest, and Money, reprint (Macmillan, London, 2007).

4. G. Cooper, The Origin of Financial Crises: Central Banks, Credit Bubbles, and the Efficient Market Fallacy (Vintage, New York, 2008).

5. A. A. Akaev and V. A. Sadovnichii, Herald Russ. Acad. Sci. 86 (5), 371-383 (2016).

6. http://data.worldbank.org/

7. A. A. Akaev, A. I. Sarygulov, and V. N. Sokolov, Dokl. Math. 92 (3), 757-760 (2015).

Translated by I. Ruzanova 